\title{
Pd(0)-Catalyzed Intramolecular $\alpha$-Arylation of Sulfones: Domino Reactions in the Synthesis of Functionalized Tetrahydroisoquinolines
}

\author{
Daniel Solé, ${ }^{*}$ Ferran Pérez-Janer, and Raffaella Mancuso ${ }^{[a]}$
}

\begin{abstract}
We report the $\operatorname{Pd}(0)$-catalyzed intramolecular $\alpha$-arylation of sulfones to give tetrahydroisoquinolines. The combination of this Pd-catalyzed reaction with intermolecular Michael and aza-Michael reactions allowed us to develop two- and three-step domino processes to synthesize diversely functionalized scaffolds from readily available starting materials.
\end{abstract}

The sulfone is a ubiquitous organic structural motif often used as an auxiliary group in important synthetic methodologies, especially those devoted to the formation of carbon-carbon bonds, in which the sulfonyl group usually acts as an electronwithdrawing moiety facilitating the deprotonation of a neighboring carbon atom. ${ }^{[1]}$ Moreover, sulfones are also present in a large number of synthetic biologically active compounds ${ }^{[2]}$ as well as in some natural products. ${ }^{[3]}$ Due to their significance, the development of new and efficient methods for the synthesis of sulfones is today an interesting challenge.

In recent years, the palladium-catalyzed arylation of acidic $\mathrm{C}-\mathrm{H}$ bonds has received a great deal of attention. ${ }^{[4]}$ However, despite the popularity of this type of reaction, examples of palladium-catalyzed $\alpha$-arylation of sulfones are scarce, probably due to the higher $p K_{\mathrm{a}}$ 's of the sulfonyl $\alpha-\mathrm{C}-\mathrm{H}$ acid, and they are limited to intermolecular processes. ${ }^{[5,6,7]}$

As part of our ongoing program on the development of efficient methodologies for the synthesis of nitrogen heterocycles,${ }^{[8]}$ we have been studying the palladium-catalyzed intramolecular coupling of amino-tethered aryl halides with enolate-type nucleophiles. ${ }^{[9]}$ To further generalize the application of the $\alpha$-arylation reaction to the synthesis of azaheterocycles, we decided to explore the use of sulfones as the nucleophilic counterpart. Additionally, we envisaged that the potential of this palladium-catalyzed reaction could be dramatically improved if, in one pot, the $\alpha$-arylation product undergoes further reaction with an electrophile such as a Michael acceptor.

To test our proposal, we focused on the synthesis of tetrahydroisoquinolines, given that this heterocyclic system is a common structural motif in pharmaceuticals and natural products. ${ }^{[10]}$ A general approach to this type of compound, using a tandem palladium-catalyzed $\alpha$-arylation and Michael addition strategy, would complement existing methodologies and in some cases provide a more attractive option. ${ }^{[11,12]}$ Herein, we report

[a] Prof. Dr. D. Solé, F. Pérez-Janer, Dr. R. Mancuso Laboratori de Química Orgànica, Facultat de Farmàcia Universitat de Barcelona

Av. Joan XXIII s/n, 08028 Barcelona, (Spain)

E-mail: dsole@ub.edu

Supporting information for this article is given via a link at the end of the document. our studies on the intramolecular palladium-catalyzed $\alpha$-arylation of $\beta$-aminosulfones, and present new domino processes based on this reaction, which allow the straightforward synthesis of diversely functionalized tetrahydroisoquinolines (Scheme 1).

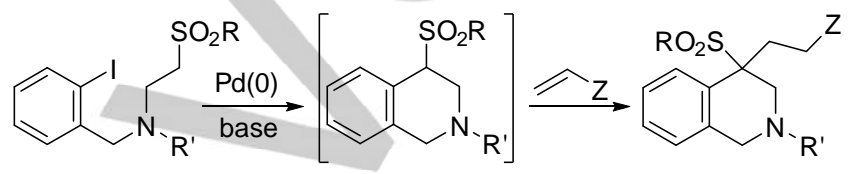

Scheme 1. Proposed tandem $\operatorname{Pd}(0)$-catalyzed $\alpha$-arylation/Michael addition of sulfones to access tetrahydroisoquinolines.

The first challenge in developing our project was to identify a suitable combination of base, catalyst and solvent for the intramolecular $\alpha$-arylation of $\beta$-aminosulfones. The sulfone 1a was chosen as a model to optimize the reaction conditions for the $\alpha$-arylation (Table 1 ). The intermolecular $\alpha$-arylation of unactivated sulfones usually requires the presence of strong bases such as $\mathrm{LiN}\left(\mathrm{SiMe}_{3}\right)_{2}$ or $\mathrm{LiO}^{t} \mathrm{Bu},{ }^{[\mathrm{c}-\mathrm{e}]}$ but in our case this was precluded by the retro-Michael degradation of the $\beta$ aminosulfone moiety (vide infra). On the other hand, treatment of $1 \mathrm{a}$ with $\mathrm{Pd}\left(\mathrm{PPh}_{3}\right)_{4}$ as the catalyst and $\mathrm{K}_{3} \mathrm{PO}_{4}$ in DMF at high temperature, an effective combination for the $\alpha$-arylation of amino acid esters, ${ }^{[9]}$ resulted in the recovery of the starting material (entry 1). A similar result was obtained when using dtpf instead of $\mathrm{PPh}_{3}$ (entry 2). The use of the ligand BINAP (entry 3) promoted the total consumption of sulfone $\mathbf{1 a}$ to give a complex reaction mixture, from which the major product, disulfone $\mathbf{3 a}$, was isolated in $22 \%$ yield. This compound is generated by the conjugated addition of the initially formed $\alpha$-arylation product $\mathbf{2 a}$ to phenyl vinyl sulfone, which arises from the partial retroMichael fragmentation of $\mathbf{1 a}$ under the reaction conditions.

The use of either $\mathrm{Cs}_{2} \mathrm{CO}_{3}$ or $\mathrm{K}_{2} \mathrm{CO}_{3}$ as the base instead of $\mathrm{K}_{3} \mathrm{PO}_{4}$, maintaining the BINAP ligand, mainly resulted in the decomposition of the starting material (entry 4), while the use of $\mathrm{Et}_{3} \mathrm{~N}$ exclusively promoted the hydrodehalogenation of the aryl iodide (entry 5). Performing the $\alpha$-arylation of $1 \mathrm{a}$ using xantphos as the ligand and $\mathrm{K}_{3} \mathrm{PO}_{4}$ as the base afforded the desired tetrahydroisoquinoline $2 \mathrm{a}$ in $59 \%$ yield, together with a small amount of disulfone $3 \mathbf{a}$ (entry 6). Under the same reaction conditions, changing the base to $\mathrm{Cs}_{2} \mathrm{CO}_{3}$ resulted in a slightly lower yield (entry 7), but gratifyingly, changing the solvent for either THF or toluene increased the yield up to $90 \%$ (entries 8-9).

Before embarking on our final challenge, the development of a tandem process, we decided to further explore the scope of $\alpha$-arylation, extending our studies to methyl sulfones and substrates bearing a phenyl or a methyl group at the nitrogen atom (Table 2). 
Table 1. Optimization of the $\alpha$-arylation conditions. ${ }^{[a]}$

\begin{tabular}{|c|c|c|c|c|c|}
\hline & $\int_{\mathrm{a}}^{\mathrm{SO}_{2} \mathrm{Ph}} \frac{\mathrm{Pd}}{\mathrm{ba}}$ & & $\mathrm{D}_{2} \mathrm{Ph}$ & 3 & $\mathrm{SO}_{2} \mathrm{Ph}$ \\
\hline Entry & $\begin{array}{l}{[\mathrm{Pd}][\mathrm{mol} \%]} \\
\text { ligand [mol \%] }\end{array}$ & Base & Solvent & $t[\mathrm{~h}]$ & 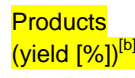 \\
\hline 1 & $\mathrm{Pd}\left(\mathrm{PPh}_{3}\right)_{4}(10)$ & $\mathrm{K}_{3} \mathrm{PO}_{4}$ & DMF & 48 & $1 a^{[c]}$ \\
\hline 2 & $\begin{array}{l}\mathrm{Pd}_{2}(\mathrm{dba})_{3}(5) \\
\mathrm{dtpf}(10)\end{array}$ & $\mathrm{K}_{3} \mathrm{PO}_{4}$ & DMF & 24 & $1 a^{[c],[d]}$ \\
\hline 3 & $\begin{array}{l}\mathrm{Pd}_{2}(\mathrm{dba})_{3}(5) \\
\text { BINAP (10) }\end{array}$ & $\mathrm{K}_{3} \mathrm{PO}_{4}$ & DMF & 72 & $3 \mathbf{a}(22)^{[\mathrm{e}]}$ \\
\hline 4 & $\begin{array}{l}\mathrm{Pd}_{2}(\mathrm{dba})_{3}(5) \\
\operatorname{BINAP}(10)\end{array}$ & $\mathrm{Cs}_{2} \mathrm{CO}_{3}$ & DMF & 72 & $-{ }^{[f]},[g]$ \\
\hline 5 & $\begin{array}{l}\mathrm{Pd}_{2}(\mathrm{dba})_{3}(5) \\
\operatorname{BINAP}(10)\end{array}$ & $\mathrm{Et}_{3} \mathrm{~N}(3)$ & DMF & 72 & $-{ }^{[h]}$ \\
\hline 6 & $\begin{array}{l}\mathrm{Pd}_{2}(\mathrm{dba})_{3}(7.5) \\
\text { xantphos }(15)\end{array}$ & $\mathrm{K}_{3} \mathrm{PO}_{4}$ & DMF & 43 & $\begin{array}{l}2 \mathbf{a}(59) \\
3 \mathbf{a}(10)\end{array}$ \\
\hline 7 & $\begin{array}{l}\mathrm{Pd}_{2}(\mathrm{dba})_{3}(7.5) \\
\text { xantphos }(15)\end{array}$ & $\mathrm{Cs}_{2} \mathrm{CO}_{3}$ & DMF & 72 & $\begin{array}{l}2 a(50) \\
3 a(9)\end{array}$ \\
\hline 8 & $\begin{array}{l}\mathrm{Pd}_{2}(\mathrm{dba})_{3}(7.5) \\
\text { xantphos }(15)\end{array}$ & $\mathrm{K}_{3} \mathrm{PO}_{4}$ & THF & 68 & $2 \mathbf{a}(90)^{[i]}$ \\
\hline 9 & $\begin{array}{l}\mathrm{Pd}_{2}(\mathrm{dba})_{3}(7.5) \\
\text { xantphos }(15)\end{array}$ & $\mathrm{K}_{3} \mathrm{PO}_{4}$ & toluene & 72 & 2a (89) \\
\hline
\end{tabular}

[a] Reaction conditions: 1a $(0.2 \mathrm{mmol}),[\mathrm{Pd}]$ and ligand (see table), and base (3 equiv.) in the indicated solvent at $120^{\circ} \mathrm{C}$ in a sealed tube. [b] Isolated yield by flash chromatography. [c] Not quantified. [d] Minor amounts of 2a were observed in the reaction mixture. [e] Minor amounts of $\mathbf{2 a}$ and the hydrodehalogenation product were observed in the reaction mixture. [f] Complex reaction mixture. [g] The use of $\mathrm{K}_{2} \mathrm{CO}_{3}$ as the base afforded a similar result. [h] Significant amounts of the hydrodehalogenation compound were observed in the reaction mixture. [i] The use of $5 \mathrm{~mol} \%$ of $\mathrm{Pd}_{2}(\mathrm{dba})_{3}$ resulted in the recovery of $10 \%$ of $1 \mathrm{a}$ after $62 \mathrm{~h}$ of reaction.

Methyl sulfone $\mathbf{1 b}$ was less efficient than phenyl sulfone $\mathbf{1 a}$ in the annulation reaction. The lower acidity of the $\alpha-\mathrm{C}-\mathrm{H}$ bonds of the methyl sulfone made its $\alpha$-arylation more troublesome and resulted in the formation of significant amounts of the hydrodehalogenation compound $\mathbf{4 b}$ (entries 1-3). Nevertheless, the yield of the $\alpha$-arylation compound $2 \mathrm{~b}$ remained reasonably high at $66 \%$ when using THF as the solvent. In contrast, sulfones 1c-d, which bear a phenyl substituent at the nitrogen, were less amenable to undergoing $\alpha$-arylation. While compound 2c was obtained in an acceptable $45 \%$ yield starting from phenyl sulfone 1c (entry 5), the annulation reaction from methyl sulfone 1d leading to $\mathbf{2 d}$ proceeded more slowly and was accompanied by an increase of the hydrodehalogenation reaction (entries 7-8) Finally, the $\alpha$-arylation from sulfone $1 \mathrm{e}$, which bears a methyl group at the nitrogen, afforded isoquinoline $2 \mathrm{e}$ in $52 \%$ yield (entry 9). As can be seen in Tables 1 and 2, the $\alpha$-arylation of $\beta$ (2-iodobenzylamino) sulfones seems to be somewhat substratedependent, the best results being obtained when using phenyl sulfones. Although the reaction tolerates the presence of the phenyl and methyl groups at the nitrogen atom, the $\mathrm{N}$-benzyl substituted substrates afforded the highest yields. Finally, the best solvents were the polar THF and DMF.

Table 2. Substrate scope in the $\alpha$-arylation reaction. ${ }^{[a]}$

\begin{tabular}{|c|c|c|c|c|}
\hline $\begin{array}{l}1 \mathrm{~b}, \\
1 \mathrm{c}, \\
1 \mathrm{~d}, \\
1 \mathrm{e},\end{array}$ & $\begin{array}{l}R^{\prime}=B n \\
R^{\prime}=P h \\
R^{\prime}=P h \\
R^{\prime}=M e\end{array}$ & & $\mathrm{O}_{2} \mathrm{R}$ & $\mathrm{SO}_{2} \mathrm{R}$ \\
\hline Entry & Sulfone & Solvent & \multicolumn{2}{|c|}{ Products (yield [\%]) } \\
\hline 1 & $1 b$ & DMF & 2b (63) & $\mathbf{4 b}(10)$ \\
\hline 2 & 1 & THF & 2b (66) & $4 b(11)$ \\
\hline 3 & 1b & toluene & $2 b(38)$ & $4 b(24)$ \\
\hline 4 & $1 c$ & DMF & $2 c(14)^{[\mathrm{c}]}$ & \\
\hline 5 & $1 c$ & THF & $2 c(45)^{[d]}$ & \\
\hline 6 & $1 \mathrm{c}$ & toluene & $2 c(19)^{[c]}$ & \\
\hline 7 & 1d & DMF & $2 \mathbf{d}(31)$ & $\mathbf{4 d}(10)$ \\
\hline 8 & 1d & THF & $1 d / 2 d / 4 c$ & $: 1)^{[\mathrm{e}]}$ \\
\hline 9 & $1 e$ & DMF & $2 e(52)$ & \\
\hline
\end{tabular}

[a] Reaction conditions: $\mathrm{Pd}_{2}(\mathrm{dba})_{3}(7.5 \mathrm{~mol} \%)$, xantphos (15 mol\%), $\mathrm{K}_{3} \mathrm{PO}_{4}$ (3 equiv.), and solvent at $120 \stackrel{\circ}{\circ}$ for $72 \mathrm{~h}$ in a sealed tube. [b] Isolated yield by flash chromatography. [c] Complex mixture. [d] Traces of the hydrodehalogenation compound $(\leq 5 \%)$ were also observed in the crude reaction mixture. [e] ${ }^{1} \mathrm{H}$ NMR ratio, yields not quantified.

With this information in hands, without further optimization, we centered our efforts on the development of a tandem intramolecular $\alpha$-arylation/Michael addition process to give access to more functionalized tetrahydroisoquinolines (Table 3). The unexpected formation of significant amounts of disulfone $\mathbf{3 a}$ in the $\alpha$-arylation reactions of $\mathbf{1 a}$ when using DMF as the solvent (Table 1, entries 3 and 6 ), was a promising starting point. Gratifyingly, treatment of $1 \mathrm{a}$ with a catalytic amount of the couple $\mathrm{Pd}_{2}(\mathrm{dba})_{3} / \mathrm{BINAP}$ and $\mathrm{K}_{3} \mathrm{PO}_{4}$ in the presence of phenyl vinyl sulfone ${ }^{[13]}$ in DMF afforded disulfone $\mathbf{3 a}$ in $71 \%$ yield (Table 3 , entry 1). The use of xantphos as the ligand improved the yield to $85 \%$ (entry 2). However, changing the solvent to either THF or toluene failed to promote the tandem process, and led to the formation of mixtures of the $\alpha$-arylation compound $2 \mathbf{a}$ and the Heck product 5 a (Scheme 2). While 2a (52\%) was the major product with THF, 5a was isolated in $59 \%$ yield when the reaction was run in toluene.

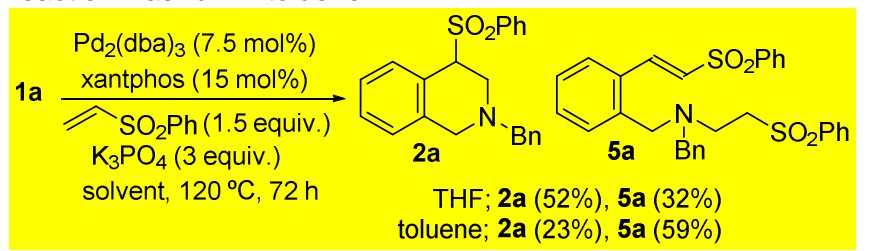

Scheme 2. Formation of Heck-type product 5a. 


\begin{tabular}{|c|c|c|c|c|}
\hline & & 1a-e & $\begin{array}{c}\mathrm{Pd}_{2}(\mathrm{dba})_{3}(7.5 \mathrm{~mol} \%) \\
\text { ligand }(15 \mathrm{~mol} \%) \\
\mathrm{Z}(1.3-1.5 \text { equiv. }) \\
\mathrm{K}_{3} \mathrm{PO}_{4}(3 \text { equiv. }) \\
\mathrm{DMF}, 120^{\circ} \mathrm{C}, 72 \mathrm{~h}\end{array}$ & \\
\hline Entry & Sulfone & Michael Acceptor & Ligand & \\
\hline 1 & $1 a$ & $\mathrm{SO}_{2} \mathrm{Ph}$ & BINAP & $3 \mathbf{a}(71)$ \\
\hline 2 & $1 a$ & $\mathrm{SO}_{2} \mathrm{Ph}$ & Xantphos & $3 a(85)$ \\
\hline 3 & $1 a$ & $\mathrm{SO}_{2} \mathrm{Me}$ & Xantphos & $6(65)^{[c]}$ \\
\hline 4 & $1 \mathrm{~b}$ & $\mathrm{SO}_{2} \mathrm{Me}$ & Xantphos & $3 b(56)^{[d]}$ \\
\hline 5 & $1 \mathrm{~b}$ & $\mathrm{SO}_{2} \mathrm{Me}$ & Xantphos & $3 b(51)^{[e]}$ \\
\hline 6 & $1 \mathrm{~b}$ & $\mathrm{SO}_{2} \mathrm{Ph}$ & antphos & $7(62)^{[f]}$ \\
\hline 7 & $1 c$ & $\mathrm{SO}_{2} \mathrm{Ph}$ & r & $3 c(68)$ \\
\hline 8 & 1d & & & $3 d(42)$ \\
\hline 9 & $1 e$ & $\mathrm{SO}_{2} \mathrm{Ph}$ & & $3 e(54)$ \\
\hline 10 & 1a & $\mathrm{CO}_{2} \mathrm{Me}$ & Xantphos & $8(63)$ \\
\hline 11 & $1 a$ & & Xantphos & $9(40)$ \\
\hline 12 & 1a & & Xantphos & $10(35)$ \\
\hline 13 & $1 b$ & & Xantphos & $11(45)$ \\
\hline
\end{tabular}

[a] Reaction conditions: $\mathrm{Pd}_{2}(\mathrm{dba})_{3}(7.5 \mathrm{~mol} \%)$, BINAP or xantphos $(15 \mathrm{~mol} \%)$, Michael acceptor $\left(1.3-1.5\right.$ equiv.), and $\mathrm{K}_{3} \mathrm{PO}{ }_{4}(3 \mathrm{equiv}$.) in $\mathrm{DMF}$ at 120 \% $\mathrm{C}$ for $72 \mathrm{~h}$ in a sealed tube. [b] Isolated yield by flash chromatography. [c] $\mathbf{3 b}(7 \%)$ was also isolated. [d] Trace amounts $(<5 \%)$ of $\mathbf{2 b}$ and $\mathbf{4 b}$ were also isolated. [e] $\mathrm{Cs}_{2} \mathrm{CO}_{3}(3$ equiv.) was used as the base. [f] 2.5 equiv. of Michael acceptor were used. 
Sulfone $\mathbf{1 b}$ afforded inferior results in the tandem reaction with methyl vinyl sulfone due to the lower acidity of the methyl sulfone $\alpha-C-H$ bond as well as the lower electrophilicity of methyl vinyl sulfone as the Michael acceptor (entries 4-5). Interestingly, "crossed" tandem processes leading to the orthogonally-substituted disulfones $\mathbf{6}$ and $\mathbf{7}$ were also promoted when starting from $\mathbf{1 a}$ and $\mathbf{1 b}$, respectively (entries 3 and 6 ).

On the other hand, sulfones $\mathbf{1 c}$ and $\mathbf{1 d}$, which bear a phenyl substituent at the nitrogen atom, failed to undergo the tandem process when using the ligand xantphos (results not included in the table). While 1c afforded a complex reaction mixture due to readily decomposing by retro-Michael fragmentation, the lower acidity of the methyl sulfone $\mathbf{1 d}$ resulted in the exclusive formation of the Heck-type product $\mathbf{5 d}$, which was isolated in $71 \%$ yield (Scheme 3 ). However, changing the ligand for BINAP allowed $1 \mathrm{c}$ and $\mathbf{1 d}$ to readily undergo the tandem processes, leading to $3 \mathbf{c}(68 \%)$ and $3 \mathbf{d}(42 \%)$, respectively (entries $7-8)$.

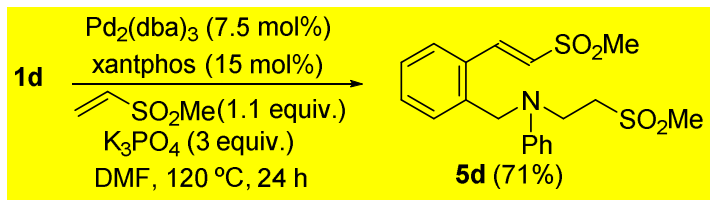

Scheme 3. Formation of Heck-type product $\mathbf{5 d}$.

Finally, the $\alpha$-arylation/conjugated addition tandem process was also extended to the use of acrylic acid esters as Michael acceptors, which allowed the preparation of $\gamma$-sulfonylesters 8-11 in acceptable yields when using xantphos as the ligand (entries 10-13).

As it was desirable to simplify the synthesis of symmetrically substituted disulfones (i. e. 3a-e), we also attempted a domino aza-Michael addition/ $\alpha$-arylation/Michael addition process starting from the readily available $\mathrm{N}$-alkyl-2-iodobenzylamines (Scheme 4). The development of such a three-step domino process would generate a high level of molecular complexity in one operation, minimising the expenditure of solvents, reagents, time, and energy. ${ }^{[14]}$

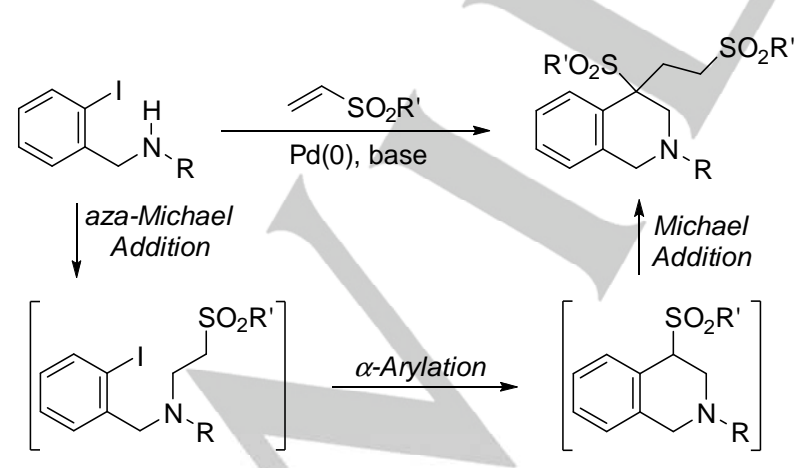

Scheme 4. Proposed domino aza-Michael addition/Pd(0)-catalyzed $\alpha$ arylation/Michael addition to access tetrahydroisoquinolines.
The results shown in Table 4 demonstrate the viability of our proposal. To our delight, the reaction of $\mathrm{N}$-benzyl-2iodobenzylamine with 2.2 equiv. of phenyl vinyl sulfone in the presence of $\mathrm{K}_{3} \mathrm{PO}_{4}$, and using the couple $\mathrm{Pd}_{2}(\mathrm{dba})_{3} /$ xantphos as the catalyst in DMF, afforded disulfone $3 a$ in $83 \%$ yield. When methyl vinyl sulfone was used as the Michael acceptor in the domino process, 3 b was obtained in $49 \%$ yield. Under the same reaction conditions and using phenyl vinyl sulfone as the Michael acceptor, N-methyl-2-iodobenzylamine afforded disulfone $3 \mathrm{e}$ in $64 \%$ yield. The yields of these domino processes are similar to those obtained in the corresponding tandem reactions (see Table 3, entries 2, 4 and 9), which indicates that the initial aza-Michael addition takes place without any interference from the competitive Heck reaction. ${ }^{[14]}$ In this context, it should be noted that although one-pot aza-Michael addition/ $\operatorname{Pd}(0)$-catalyzed $\alpha$-arylation processes using acrylates have been reported, ${ }^{[11 b]}$ it has been impossible to develop a real domino process ${ }^{[15]}$ because, in the presence of the Pd catalyst, the Heck reaction with the acrylate takes precedence over the aza-Michael addition. ${ }^{[12,16]}$ The success of the present domino process with vinyl sulfones may be due to the poor behaviour of sulphur-substituted olefins in the Heck reaction. ${ }^{[17]}$

Table 4. Domino aza-Michael addition/ $\alpha$-arylation/Michael addition process. ${ }^{[a]}$

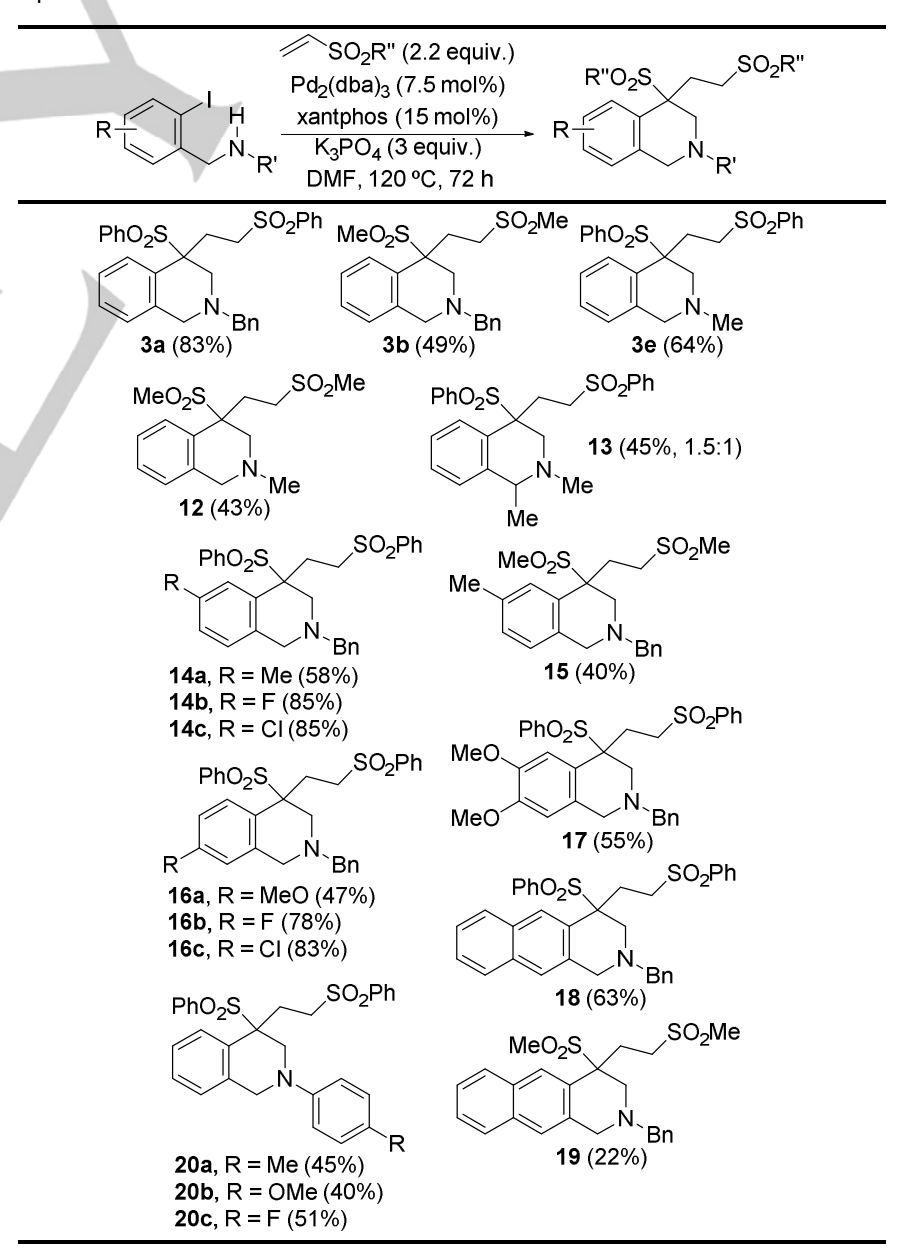

[a] Reaction conditions: $\mathrm{Pd}_{2}(\mathrm{dba})_{3}(7.5 \mathrm{~mol} \%)$, xantphos (15 mol\%), vinyl sulfone (2.2 equiv.), and $\mathrm{K}_{3} \mathrm{PO}_{4}$ (3 equiv.) in DMF at $120{ }^{\circ} \mathrm{C}$ for $72 \mathrm{~h}$ in a 
sealed tube.

The scope of the domino aza-Michael addition/ $\alpha$ arylation/Michael addition reaction for the synthesis of diversely functionalized disulfones was then examined. Overall, as also observed in the tandem processes (Table 3 ), phenyl sulfones afforded better results than methyl sulfones in the three-step domino reaction. The higher acidity of the $\alpha-\mathrm{C}-\mathrm{H}$ bonds of the phenyl sulfone favors both the $\alpha$-arylation and the Michael addition, while the higher electrophilicity of phenyl vinyl sulfone benefits the Michael addition reactions.

The domino reaction also proceeded smoothly from 2iodobenzylamines bearing either electron-donating ( $\mathrm{Me}, \mathrm{OMe})$ or electron-withdrawing groups $(\mathrm{Cl}, \mathrm{F})$ on the aromatic ring, the latter affording higher yields. Considering that the yields of the domino process essentially reflect the yield of the $\alpha$-arylation reaction, these results seem to indicate that the 2iodobenzylamines with electron-withdrawing groups show better behaviour in the palladium-catalyzed reaction than those bearing electron-donating groups. Finally, naphtho-fused heterocycles (18 and 19) and tetrahydroisoquinolines bearing aryl groups on the nitrogen atom (20a-c) were accessible through the domino reaction.

In summary, we have developed efficient synthetic methods toward diversely functionalized tetrahydroisoquinolines based on the intramolecular $\operatorname{Pd}(0)$-catalyzed $\alpha$-arylation of sulfones. The combination of the $\mathrm{Pd}$-catalyzed reaction with intermolecular Michael and aza-Michael reactions allowed us to develop twoand three-step domino processes to synthesize diversely functionalized scaffolds from readily available starting materials. Further exploration to expand the scope of these domino processes to other heterocyclic systems is underway in our laboratory and will be reported in due course.

\section{Experimental Section}

\section{General procedure for the three-step domino reactions}

A mixture of $N$-benzyl-2-iodobenzylamine $(65 \mathrm{mg}, 0.20 \mathrm{mmol}), \mathrm{Pd}_{2}(\mathrm{dba})_{3}$ $(14 \mathrm{mg}, 0.015 \mathrm{mmol})$, xantphos (17 mg, $0.03 \mathrm{mmol})$, phenyl vinyl sulfone (74 mg, $0.44 \mathrm{mmol})$, and $\mathrm{K}_{3} \mathrm{PO}_{4}(127 \mathrm{mg}, 0.60 \mathrm{mmol})$ in DMF $(8 \mathrm{~mL})$ was stirred at $120{ }^{\circ} \mathrm{C}$ in a sealed tube for $72 \mathrm{~h}$. The reaction mixture was poured into water and extracted with $\mathrm{Et}_{2} \mathrm{O}$. The organic extracts were washed with brine, dried, and concentrated. The residue was purified by flash chromatography $\left(\mathrm{SiO}_{2}\right.$, from $\mathrm{CH}_{2} \mathrm{Cl}_{2}$ to $\left.\mathrm{CH}_{2} \mathrm{Cl}_{2}-\mathrm{MeOH} 1 \%\right)$ to give disulfone $3 \mathbf{a}(88 \mathrm{mg}, 83 \%)$.

\section{Acknowledgements}

We gratefully acknowledge financial support for this work from Spanish MINECO-FEDER Project CTQ2012-31391.

Keywords: $\alpha$-arylation $\cdot$ domino reactions $\cdot$ palladium $\bullet$ sulfones - tetrahydroisoquinolines
[1] a) N. S. Simpkins, Sulphones in Organic Synthesis, Pergamon Press: Oxford, 1993; b) D. Alonso, M. Fuensanta, C. Nájera, M. Varea, Phosphorus, Sulfur and Silicon Relat. Elem. 2005, 180, 1119; c) A.-N. R. Alba, X. Companyó, R. Rios, Chem. Soc. Rev., 2010, 39, 2018; d) M. Nielsen, C. B. Jacobsen, N. Holub, M. W. Paixao, K. A. Jorgensen, Angew. Chem. Int. Ed. 2010, 49, 2668.

[2] See, for example: a) L. Garuti, M. Roberti, D. Pizzirani, G. Poggi, Curr. Med. Chem. 2005, 4, 167; b) S. Sabatini, G. W. Kaatz, G. M. Rossolini, D. Brandini, A. Fravolini, J. Med. Chem. 2008, 51, 4321; c) T. K. Sasikumar, L. Qiang, D. A. Burnett, D. Cole, R. Xu, H. Li, W. J. Greenlee, J. Clader, L. Zhang, L. Hyde, Bioorg. Med. Chem. Lett. 2010, 20, 3632; d) N. Gautam, Y. Dixit, R. Dixit, S. K. Gupta, D. C. Gautam, Phosphorus, Sulfur and Silicon Relat. Elem. 2013, 188, 1127.

[3] a) M. R. Prinsep, J. W. Blunt, M. H. G. Munro, J. Nat. Prod. 1991, 54, 1068; b) S. Cao, C. Foster, M. Brisson, J. S. Lazo, D. G. I. Kingston, Bioorg. Med. Chem. 2005, 13, 999; c) F. Yang, M. T. Hamann, Y. Zou, M.-Y. Zhang, X.-B. Gong, J.-R. Xiao, W.-S. Chen, H.-W. Lin, J. Nat. Prod. 2012, 75, 774; d) E. P. Stout, L. C. Yu, T. F. Molinski, Eur. J. Org. Chem. 2012, 5131.

[4] For reviews, see: a) D. A. Culkin, J. F. Hartwig, Acc. Chem. Res. 2003, 36, 234; b) F. Bellina, R. Rossi, Chem. Rev. 2010, 110, 1082; c) C. C. C. Johansson, T. J. Colacot, Angew. Chem. Int. Ed. 2010, 49, 676.

[5] a) A. N. Kashin, A. V. Mitin, I. P. Beletskaya, R. Wife, Tetrahedron Lett. 2002, 43, 2539; b) T. Niwa, H. Yorimitsu, K. Oshima, Tetrahedron 2009, 65,1971 ; c) G. Zhou, P. C. Ting, R. G. Aslanian, Tetrahedron Lett. 2010, 51, 939; d) B. Zheng, T. Jia, P. J. Walsh, Org. Lett. 2013, 15, 1690; e) M. Nambo, C. M. Crudden, Angew. Chem. Int. Ed. 2014, 53, 742.

[6] For the intermolecular $\alpha$-arylation of sulfoxides, see: a) T. Jia, A. Bellomo, K. El Baina, S. D. Dreher, P. J. Walsh, J. Am. Chem. Soc. 2013, 135, 3740; b) T. Jia, A. Bellomo, S. Montel, M. Zhang, K. El Baina, B. Zheng, P. J. Walsh, Angew. Chem. Int. Ed. 2014, 53, 260.

[7] For the intermolecular $\alpha$-arylation of sultams, see: O. René, B. P. Fauber, S. Malhotra, H. Yajima, Org. Lett. 2014, 16, 3468.

[8] a) D. Solé, E. Peidró, J. Bonjoch, Org. Lett. 2000, 2, 2225; b) D. Solé, F. Diaba, J. Bonjoch, J. Org. Chem. 2003, 68, 5746; c) D. Solé, X. Urbaneja, J. Bonjoch, Adv. Synth. Catal. 2004, 346, 1646.

[9] a) D. Solé, L. Vallverdú, Bonjoch, Adv. Synth. Catal. 2001, 343, 439; b) D. Solé, L. Vallverdú, X. Solans, M. Font-Bardia, J. Bonjoch, J. Am. Chem. Soc. 2003, 125, 1587; c) D. Solé, X. Urbaneja, J. Bonjoch, Tetrahedron Lett. 2004, 45, 3131; d) D. Solé, O. Serrano, J. Org. Chem. 2008, 73, 2476; e) D. Solé, O. Serrano, J. Org. Chem. 2008, 73, 9372; f) D. Solé, O. Serrano, Org. Biomol. Chem., 2009, 7, 3382; g) D. Solé, O. Serrano, J. Org. Chem. 2010, 75, 6267; h) D. Solé, M.-L. Bennasar, I. Jiménez, Org. Biomol. Chem., 2011, 9, 4535; i) D. Solé, I. Fernández, M. A. Sierra, Chem. Eur. J. 2012, 18, 6950; j) D. Solé, F. Mariani, I. Fernández, M. A. Sierra, J. Org. Chem. 2012, 77, 10272; k) D. Solé, I. Fernández, Acc. Chem. Res. 2014, 47, 168.

[10] For recent reviews, see: a) K. W. Bentley, Nat. Prod. Rep., 2006, 23, 444; b) P. Siengalewicz, U. Rinner, J. Mulzer, Chem. Soc. Rev., 2008, 37, 2676; c) K. Bhadra, G. S. Kumar, Mini-Reviews in Medicinal Chemistry, 2010, 10, 1235 d) A. L. Souto, J. F. Tavares, M. Sobral da Silva, M. F. F. M. Diniz, P. Filgueiras de Athayde-Filho, J. M. BarbosaFilho, Molecules, 2011, 16, 8515 e) P. E. Alford, Progress in Heterocyclic Chemistry 2011, 23, 329.

[11] For the $\alpha$-arylation of $\beta$-aminoesters leading to tetrahydroisoquinolines, see: a) A. G. K. Reddy, J. Krishna, G. Satyanarayana, Synlett 2011, 1756; b) A. G. K. Reddy, G. Satyanarayana, Tetrahedron 2012, 68, 8003.

[12] For domino Heck/aza-Michael reactions leading to isoindolines and tetrahydroisoquinolines, see: a) D. L. Priebbenow, S. G. Stewart, F. M. Pfeffer, Org. Biomol. Chem., 2011, 9, 1508; b) D. L. Priebbenow, F. M. Pfeffer, S. G. Stewart, Eur. J. Org. Chem. 2011, 1632; c) K. Chen, S. A. Pullarkat, Org. Biomol. Chem., 2012, 10, 6600; d) Q. Zang, S. Javed, P. Porubsky, F. Ullah, B. Neuenswander, G. H. Lushington, F. Z. Basha, M. G. Organ, P. R. Hanson, ACS Combi. Sci. 2012, 14, 211. 
[13] For the conjugate addition of carbon nucleophiles to vinyl sulfones, see: Y.-X. Xie, R.-J. Song, Y. Liu, Z.-Q. Wang, J.-N. Xiang, J.-H. Li, Synthesis, 2014, 46, 203, and references therein.

[14] In fact, no product resulting from the initial Heck coupling of the aryl halide with the vinyl sulfone was observed in any of the runs shown in Table 4.

[15] L. F. Tietze, Chem. Rev. 1996, 96, 115.
[16] For the $\operatorname{Pd}(0)$-catalyzed cyclocarbonylation of 2-iodobenzylamines with Michael acceptors, see: K. Okuro, H. Alper, Synlett 2012, 2531.

[17] See for example: D. G. Bachmann, C. C. Wittwer, D. G. Gillingham, Adv. Synth. Catal. 2013, 355, 3703, and references therein. 


\section{Entry for the Table of Contents}

\section{COMMUNICATION}

$$
\text { (I: }
$$

A new strategy for the synthesis of tetrahydroisoquinolines based on the $\operatorname{Pd}(0)$ catalyzed intramolecular $\alpha$-arylation of sulfones is reported. The combination of this $\mathrm{Pd}$-catalyzed reaction with intermolecular Michael and aza-Michael reactions allowed us to develop two- and three-step domino processes to synthesize diversely functionalized scaffolds from readily available starting materials.
Daniel Solé, * Ferran Pérez-Janer, and Raffaella Mancuso

Page No. - Page No.

$\operatorname{Pd}(0)$-Catalyzed Intramolecular $\alpha$ Arylation of Sulfones: Domino Reactions in the Synthesis of Functionalized

Tetrahydroisoquinolines 